\title{
Interdigital transfer of kinesthetic after-effects
}

RICHARD W. THOMPSON, RICHARD ENTER AND JOHN TARPINIAN

OHIO UNIVERSITY

Two experiments investigated the effect of using a different finger for inspection (I) than is used in making judgments on the size of a kinesthetic aftereffect (KAE). Experiment I investigated transfer of I stimulation of the ring finger to judgments made with the index finger: A control group used the index finger for both judgments and I period. Results indicated significant $\mathrm{KAE}$ for both groups. Experiment II replicated Experiment I except the second finger was used to test for transfer of I stimulation to judgments made with the index finger. Results indicated KAE for only the control group which used the index finger for both judgments and I stimulation.

Although the procedures for inducing kinesthetic after-effects (KAE) have been investigated for such variables as size of the inspection (I) stimulus (Charles \& Duncan, 1959), amount and distribution of I trials (Carlson, 1963), and attention to the I stimulus (Bakan \& Thompson, 1963), there has been no investigation of the role of the fingers used during I stimulation and for judgments on the size of KAE. Charles and Duncan (1959) have demonstrated a distance gradient in KAE; I stimuli either much larger or smaller than test (T) stimuli result in little or no KAE. The distance gradient is predictable on the basis of satiation theory (Kohler \& Dinnerstein, 1947). A similar gradient would be expected if, instead of varying the size of the I stimulus, the finger used during the I period was different from the finger used to make judgments. The present experiments investigated the transfer effects between $I$ and judgment fingers in obtaining $\mathrm{KAE}$ 。

\section{EXPEPIMENT I}

\section{Method}

Subjects. Thirty males were randomly assigned to two groups of 15 each. Group $C_{1}$ was a control group and used the thumb and index finger for the $I$ period and pre and post judgments. Group $\mathrm{E}_{1}$ used the thunb and index finger for pre and post judgments and the thumb and ring finger for the I period.

Apparatus, The apparatus was made of wood and consisted of a $\mathrm{T}$ block $1-1 / 2 \mathrm{in}$. wide and an I block $1 / 2$ in. wide. Both $T$ and I blocks were 28 in. long. The variable stimulus (V) was a wedge 62 in. long which tapered from 3 in. to $1-1 / 16$ in., a decrease of $1 / 32$ in. per inch of length. All stimuli were 1-3/4 in. thick. An $\mathrm{H}$-shaped piece of wood which slid on a steel rod on the top of each of the stimuli ensured that $S$ 's finger and thumb were parallel.

Prucdure. Each $\mathrm{S}$ was met outside the experimental room and given instruction on how to make judgments by the "zeroing in" method. Then $\mathrm{S}$ was blindfolded and was led into the experimental room between the two tables which held the apparatus. The wedge was held in the preferred hand and the $T$ or I stimuli in the non-preferred hand. The S made four pre I judgments in an ADDA ascending-descending order. The S started each judgment $1 / 4$ in. wider or narrower than the POE. The $S$ was encouraged to make judgments within $15 \mathrm{sec}$. The $S$ then rested his preferred hand at his side and rubbed the I block, with the appropriate finger and thumb, at a rate of 60 strokes per minute for one minute. At the end of the I period S rested both hands at his side. The $E$ picked up the $T$ block, walked across the room, placed it on a table, picked it up, and returned it to the table next to $S$. The $E$ then told $S$, "Now you are going to make some more judgments of a block of wood." It was hoped that movement of the $\mathrm{T}$ block in this way would increase the magnitude of $\mathrm{KAE}$ since $\mathrm{S}$ would not know whether he was judging the same or a different $T$ block. Movement of the $T$ block took less than $10 \mathrm{sec}$. The $S$ then made four post I judgments in the same way as he made pre I judgments.

\section{Results}

The mean pre and post judgment for each $\mathrm{S}$ was used to compute a Lindquist (1953) Type I analysis of variance. Groups means are presented in Table 1. Results indicated only a significant pre to post judgment difference $(F=19.25, \mathrm{df}=1 / 28, \mathrm{p}<.001)$. Failure to obtain a significant difference between groups or a groups by judgments interaction indicated that both Group $\mathrm{C}_{1}$ and $\mathrm{E}_{1}$ showed a significant $\mathrm{KAE}$.

\section{EXPERIMENT II}

Experiment II was an attempt to replicate Experiment $I$ and obtain data on a different transfer finger. Method

Subjects. Thirty males were randomly assigned to two groups of 15 each. Group $\mathrm{C}_{2}$ used the thumb and index finger for all judgments and the I period. Group $\mathrm{E}_{2}$ used the thumb and index finger to make pre and post judgments and the middle finger for the I period.

Table 1. Mean KAE in Inches Based on Pre and Post Inspection Judgments

\begin{tabular}{ccccc} 
& \multicolumn{3}{c}{ For Experiment } & \multicolumn{2}{c}{ and Experiment II } \\
Eroup & Pre & Post & Difference \\
\hline & $C_{1}$ & 1.594 & 1.727 & 0.133 \\
\hline \multirow{2}{*}{ Expt. I } & $E_{1}$ & 1.645 & 1.713 & 0.068 \\
\hline & $C_{2}$ & 1.558 & 1.658 & 0.100 \\
& $E_{2}$ & 1.542 & 1.574 & 0.032 \\
\hline
\end{tabular}


Apparalus and Procedure. Except for the modification in finger used by the $\mathrm{E}_{2}$ group and a different $\mathrm{E}$, apparatus and procedure were identical to Experiment I.

\section{Results}

The mean pre and post judgment for each $S$ were used to compute a Type I analysis of variance. Table 1 presents group means. Results indicated no significant difference between groups but a significant pre to post judgment difference $(F=19.83, \mathbf{d f}=1 / 28, p<.001)$ and a significant group by judgments interaction $(F=5.35$, $\mathrm{df}=1 / 28, \mathrm{p}<.05)$. Further analysis by $\mathrm{t}$ tests indicated that only Group $\mathrm{C}_{2}$ showed a significant $\operatorname{KAE}(\mathrm{t}=4.79$, $\mathrm{df}=28, \mathrm{p}<.01)$.

\section{DISEUSSION}

Experiment I yielded results which are predictable from satiation theory. If the cortical representation of the distance between thumb and finger is topographically arranged so that the various fingers and thumb are represented in about the same relationship in the brain as on the hand, then the effect of satiation induced in one finger-thumb combination should be detectable at other finger-thumb combinations. It would be expected that the KAE measured with a finger other than the I finger would be smaller than the KAE measured with the I finger. These are the results of Experiment I. The results of Experiment II are surprising in that an even smaller difference between experimental and control groups would be expected since I finger and judg- ment finger are closer than in Experiment I. Experiment II results indicated a significant KAE for the control group only. Unfortunately, confounded with the change in fingers used in the two experiments was a change in Es. Both Es were trained in the same way and used the same procedure and apparatus. Other factors that could account for the difference between experiments were random variation, Ss used, and time of year. It should be noted that the results of Experiment II were in the same direction as those of Experiment I. Although unlikely, it is possible that the cortical representation of the width between thumb and index finger is closer to the cortical representation of thumb and ring finger than it is to thumb and middle finger. The data do indicate that, under certain conditions of stimulation, one finger-thumb combination can affect judgments made by another finger-thumb combination.

\section{References}

Bakan, P., \& Thompson, R. Attention and kinesthetic after-effects. Amer. J. Psychol., 1963, 76, 39-48.

Carlson, J. B. Effect of amount and distribution of inspection time and length of decay interval on kinesthetic aftereffects. $J$. exp. Psychol., 1963, 66, 377-382.

Charles, J. P., \& Duncan, C. P. The distance gradient in kinesthetic aftereffects. J. exp. Psychol., 1959, 57, 164-170.

Kohler, W., \& Dinnerstein, D. Figural aftereffects in kinesthesis. In Miscellanea psychologia Albert Michotie. Paris: Libraire Philosophique, 1947. Pp. 196-220.

(Accepted for publication October 10, 1966.) 